\title{
A Branquitude e a Cisgeneridade problematizadas na formação de professoras(es) de Ciências e Biologia: Uma proposta decolonial no estágio supervisionado
}

\author{
Whiteness and Cisgenerity problematized in the formation of Science \\ and Biology teachers: A decolonial proposal in the supervised \\ internship
}

\section{Yonier Orozco Marin ${ }^{1}$; Pâmela Nunes ${ }^{2}$; Suzani Cassiani ${ }^{3}$}

1 Programa de Pós-Graduação em Educação Científica e Tecnológica. Universidade Federal de Santa Catarina - UFSC, Santa Catarina, Brasil/ORCID 0000-0002-4095-4875

2 Programa de Pós-Graduação em Educação Científica e Tecnológica. Universidade Federal de Santa Catarina - UFSC, Santa Catarina, Brasil /ORCID 0000-0003-2992-9967.

3 Programa de Pós-Graduação em Educação Científica e Tecnológica. Universidade Federal de Santa Catarina - UFSC, Santa Catarina, Brasil - suzanicassiani@gmail.com,/ORCID 0000-0001-8824-9342

\section{Palavras-chave:}

Decolonialidade.

Educação para a Justiça social. Educação para as relações etnicorraciais. Formação de Professores. Gênero e Sexualidade.

\section{Keywords:}

Decoloniality. Education for Social Justice.

Education for ethnorracial relations.
RESUMO: As ações afirmativas propostas no vestibular nas universidades brasileiras e a luta dos movimentos sociais têm acarretado a abertura de muitas discussões até então negligenciadas na formação de professoras(es). A abordagem de questões como a luta antirracista, os feminismos, o preconceito de classe, a luta das e dos trabalhadores, o capacitismo e as dissidências sexuais e de gênero, vem incursionando no ensino de ciências e biologia não só como assuntos novos a serem incluídos, mas também como questionadores dos valores da biologia e suas formas de serem ensinadas, aprendidas e avaliadas. Esses assuntos podem ser agrupados na decolonialidade como um movimento que problematiza as relações de poder, ser e saber constituídas na história e no presente colonial da América Latina. Movimento que anuncia novos caminhos para pensar a justiça social considerando os saberes, epistemologias, corpos e práticas das pessoas desprovidas da sua humanidade pelas relações violentas da colonialidade. Neste trabalho, temos por objetivo analisar as potencialidades de uma oficina realizada no estágio supervisionado do curso de Licenciatura em Ciências Biológicas da UFSC, para problematizar a branquitude e a cisgeneridade, a partir do debate sobre os possíveis diálogos entre ensino de biologia e discursos das dissidências sexuais e de gênero de territórios colonizados. $\mathrm{Na}$ oficina abordamos o tema "a história do conceito hormônio" e utilizamos como metodologia a escrita livre coletiva. Analisamos qualitativamente as narrativas tecidas coletivamente entre professoras(es) formadoras(es) e professoras(es) em formação, e os sentidos decoloniais sobre a branquitude e a cisgeneridade mobilizados nesta escrita. Evidenciamos que o diálogo com vozes construídas pelas relações coloniais como periféricas provocam insurgências, transgressões e sentidos de justiça no ensino de ciências e biologia, tensionando o imaginário de universalidade e o lugar de privilégio da branquitude e a cisgeneridade.

\section{ABSTRACT:}

The affirmative actions proposed in the entrance exam in Brazilian universities and the struggle of social movements have led to the opening of many discussions neglected in the initial teacher education. The approach to issues such as the antiracist struggle, feminisms, class prejudice, the struggle of workers, deficiency and 
Teacher Education, Gender and Sexuality. sexual and gender dissent, has been incursing science and biology teaching not only as new subjects to be included, but also as questioners of the values of biology and their ways of being taught, learned and evaluated. These issues can be grouped in decoloniality as a movement that questions the relations of power, being and knowledge constituted in the history and colonial present of Latin America. Movement that announces new ways to think about social justice considering the knowledge, epistemologies, bodies and practices of people deprived of their humanity by the violent relations of coloniality. In this work, we aim to analyze the potentialities of a workshop held in the supervised internship of the Undergraduate Course in Biological Sciences at UFSC, to problematize whiteness and cisgenerity, from the debate on the possible dialogues between biology teaching and discourses of sexual and gender dissent from colonized territories. In the workshop, we approach the theme "the history of the hormone concept" and use collective free writing as methodology. We qualitatively analyze the narratives collectively produced by researchers and teachers in formation, about decolonial meanings and whiteness and cisgenerity, mobilized in this writing. We evidence that dialogue with voices constructed by colonial relations as peripherals, provoke insurgencies, transgressions and meanings of justice in the teaching of sciences and biology, tensioning the imaginary of universality and the place of privilege of whiteness and cisgenerity.

\section{INTRODUÇÃO}

Para contextualizar a disciplina de Estágio Supervisionado no Ensino de Ciências na Universidade Federal de Santa Catarina, quando em 2002, uma das autoras deste texto iniciou sua docência no curso de Ciências Biológicas da UFSC.

Um perfil, com um viés meritocrático, permeava o grupo de estudantes ingressantes, pois eram geralmente brancas (os), de classe média e provenientes de estados do sul e sudeste. Como a maioria havia frequentado escolas particulares, (CASSIANI \& NACIMENTO, 2006), muitos deles e delas desconheciam as escolas públicas, construindo vários estereótipos sobre as mesmas, apresentando um imaginário de escola, como um espaço inócuo para qualquer tipo de aprendizado, professores(as) pouco comprometidos(as) e que em sua maioria não gostava de sua profissão. A escola era um espaço desalentador, no qual só aconteciam greves desnecessárias e nada se ensinava.

Nesse sentido, a disciplina de Estágio na graduação sempre teve como objetivo refletir sobre a escola pública, como espaço de luta, procurando trabalhar conteúdos com enfoques sociais, educação CTS (CASSIANI \& LINSINGEN, 2009), metodologias alternativas ao livro didático, envolvendo leitura e escrita, experimentação, problematizações, diferentes avaliações, entre outras formas e conteúdo. Era um grande desafio, pois até aquele momento do estágio, muitos deles haviam vivenciado o ensino tradicional na maioria de suas aulas.

Nesse mesmo contexto, desde 2002, já trabalhávamos com os seguintes pressupostos: a escola como co-formação de professoras(es) e não um depósito de estagiárias(os) que pretendiam realizar ações verticalizadas, mas sim parcerias numa co-construção (PIMENTA, 2002); o estágio como lócus de conhecimento e não a aplicação deste; o estágio como parte do funcionamento de uma tríade - extensão, ensino e pesquisa e a importância dessa articulação com os diferentes espaços de forma horizontalizada; o estágio como um ritual de passagem de estudante à posição de professor. Enfim, a preocupação de trabalho com futuros professores que ao longo de décadas tiveram com uma formação no ensino tradicional, com um imaginário sobre esse espaço decorrente de suas histórias de vida, para uma ruptura na posição de professor(a) com uma proposta mais progressista. Para tanto, o estágio sempre teve como objetivos ênfases mais próximas em temas e realidades locais e direitos humanos, incluindo todos os seres vivos. 
Para repensar essa formação muitas eram as perguntas: qual conhecimento científico é suficiente para a superação de questões tão marcantes do mundo contemporâneo, como a fome, o racismo ou a desigualdade social? Como não ficar apenas numa postura contemplativa diante dessas condições de trabalho dos professores de ciências nas escolas? Como trabalhar com conteúdos e práticas comprometidas com as questões sociais?

Aprendizados foram e ainda são muitos e contínuos nos três espaços: escola, comunidade e universidade, articulando os estágios. Estes se retroalimentaram, culminando em análises, resultados e ações, que contribuíram para repensar aspectos internos da universidade, bem como para a co-construção de conhecimentos entre as comunidades envolvidas, ou seja, pensar a escola como co-formadora de professores.

Compreendemos que apesar dos imaginários sobre a escola, professor, estudantes, ainda estarem presentes, algo mudou. Apontamos para as ações afirmativas por políticas públicas entre elas, as cotas para negros(as) e escola pública, cuja possibilidade trouxe à tona muitas discussões que eram silenciadas, como por exemplo, a questão do racismo, classismo, patriarcado, LGBTfobia, entre outras injustiças sociais. Também, a Resolução CNE/CP $n^{\circ} 2$, de 2015 sobre as Diretrizes Curriculares Nacionais de Formação de Professores, também compôs o debate sobremaneira e um repensar sobre o currículo e a formação de professoras(es), nessa perspectiva dos Direitos Humanos e da Terra.

Para Marin (2018), os movimentos LGBTQIA+, os feminismos, os mulherismos, os movimentos negros, as comunidades indígenas, os deslocados forçadamente dos seus territórios, as prostitutas, as e os moradores de periferias, entre outros, representam processos de luta e transformação social, dos quais a educação em ciências também pode e deve fazer parte.

Neste trabalho, temos por objetivo analisar as potencialidades da disciplina Estágio Supervisionado do curso de Licenciatura em Ciências Biológicas da UFSC, através de processos que problematizam a branquitude e a cisgeneridade, em uma perspectiva decolonial, a partir do debate sobre os possíveis diálogos entre ensino de biologia e discursos das dissidências sexuais e de gênero de territórios colonizados.

\section{BRANQUITUDE E CISGENERIDADE}

Duas questões são problemáticas quando se pensam os marcadores sociais da diferença na educação. A primeira consiste em pensar estes assuntos no plano individual e do sujeito, como etiquetas que marcam e essencializam uma pessoa, desconhecendo as relações históricas e coloniais que instituíram, naturalizaram e/ou reforçaram estruturas que determinam os lugares dos corpos na nossa sociedade. Dessa maneira, pensa-se que os corpos construídos como "diferentes" nessas relações, devem ser incluídos, higienizados ou aceitos nas estruturas, mas não se questionam as estruturas em si, e muito menos, as combatem.

A segunda questão consiste na problematização dos marcadores sociais da diferença, os quais costumam estar direcionados aos corpos construídos como "diversos" ou "diferentes". Por outro lado, corpos que se situam dentro do considerado como "normais" são protegidos e universalizados, e, portanto, sem necessidade de problematização. Assim, na escola, a negritude, a identidade indígena, os corpos da diversidade funcional e das dissidências sexuais e de gênero são problematizados, enquanto a branquitude, a cisgeneridade, a heterossexualidade, a "não deficiência" são protegidas e universalizadas, enfim naturalizadas.

Em uma perspectiva decolonial, tanto a branquitude, quanto a cisgeneridade são assuntos pertinentes de problematização. Considerando que as professoras(es) e estudantes que participam da experiência relatada neste trabalho, nos incluindo também, estamos todas e todos marcados pela branquitude e a cisgeneridade, ressaltamos que é relevante problematizar 
estes marcadores no ensino de biologia, pelo lugar privilegiado que esta disciplina tem em relação aos temas do corpo.

Sobre a branquitude, Cardoso (2010) a define como "um lugar de privilégios simbólicos, subjetivos, objetivos, isto é, materiais palpáveis que colaboram para construção social e reprodução do preconceito racial, discriminação racial "injusta" e "racismo" (p. 611).

A branquitude reforça a ideia de que o sujeito branco não tem raça ou etnia e que corresponde ao padrão normativo único, o "natural". Cardoso (2010) define dois tipos de branquitude, a primeira seria crítica, na qual o sujeito branco desaprova o racismo publicamente (o que não implica necessariamente que isso seja ratificado no espaço privado), e a segunda acrítica que não admite o preconceito racial, não desaprova o racismo, e naturaliza o lugar simbólico e material do branco como superior e universal.

Schucman (2012) nos lembra que a branquitude também é uma identidade racial construída e marcada pela subjetividade. Identidade que também "tem fronteiras e distinções internas que hierarquizam os brancos através de outros marcadores sociais, como classe social, gênero, origem, regionalidade" (ibid p.108). A branquitude mais do que corresponder a uma característica inata biológica, trata-se de uma construção colonial que legitima e naturaliza privilégios e opressões, então percebemos a importância da sua problematização.

Por outro lado, a cisgeneridade é concebida socialmente como o percurso natural da biologia, da natureza, ou do mandado de um deus sobre os corpos. "Nasci homem e sou homem", "nasci mulher e sou mulher", enquanto a transgeneridade ou transexualidade é concebida como um desvio cultural em relação à natureza do corpo. Vergueiro (2015) caracteriza a cisgeneridade também como uma construção carregada de subjetividade, aspectos simbólicos e de história colonial. A autora destaca três traços interdependentes da cisnormatividade: a) Pré-discursividade, como o entendimento construído histórico, social e culturalmente de que é possível definir sexos-gêneros a partir de critérios objetivos e de características corporais independentemente de autopercepções e contextos; b) Binariedade, como a ideia de que os corpos "normais" estão definidos a partir de duas, e somente duas alternativas, caixinhas (macho/homem, fêmea/mulher); c) Permanência, como a premissa de que os corpos apresentam coerência binária, fisiológica e psicológica ao longo da vida das pessoas.

Wayar (2007) também destaca que a cisgeneridade é um regime de medo que é difundido na cultura, com a exposição morbosa dos corpos das travestis mortas e torturadas, sendo esta exposição indispensável e necessária para manter os conformes com a norma dos corpos fantasiados de sujeitos, mas que na verdade são mão de obra barata que alimentam um sistema político e econômico que os mata dia a dia. A cisgeneridade como "teatralização do medo" (ibid p. 52).

Esses temas são muito caros no trabalho com os estagiários de licenciatura, pois são temas silenciados na formação de professoras(es) e, ao mesmo tempo, temas presentes nas escolas, vide Resolução $n^{\circ} 2$, de $1^{\circ}$ de julho de 2015, das Diretrizes Curriculares Nacionais para a formação inicial em nível superior, junto ao capítulo $\mathrm{V}$ do artigo 13:

$\S 2^{\circ}$ Os cursos de formação deverão garantir nos currículos conteúdos específicos da respectiva área de conhecimento ou interdisciplinares, seus fundamentos e metodologias, bem como conteúdos relacionados aos fundamentos da educação, formação na área de políticas públicas e gestão da educação, seus fundamentos e metodologias, direitos humanos, diversidades étnico-racial, de gênero, sexual, religiosa, de faixa geracional, Língua Brasileira de Sinais (Libras), educação especial e direitos educacionais de adolescentes e jovens em cumprimento de medidas socioeducativas. (BRASIL, 2015, p.11). 
Poderíamos dizer que mesmo propostos em documentos oficiais, muitas vezes esses temas não são abordados na licenciatura, aprofundando ainda mais o racismo estrutural e LGTfobia.

\section{DECOLONIALIDADE}

Neste trabalho pensamos a decolonialidade como referente político, teórico e metodológico que pode nos sulear nesta tarefa de problematizar a branquitude e a cisgeneridade como elementos conflitivos na formação de professoras(es) de biologia. Adotamos esse referencial teórico na perspectiva decolonial, pois consideramos que este contribui com a discussão da branquitude e suas marcas sociais, bem como as injustiças sociais, as quais são marcas da colonização. Portanto, com os estudos decoloniais, problematizamos o mundo em que vivemos, instigando as(os) estagiárias(os) a pensarem para além de sua realidade social, em um processo de alteridade com o outro, repensando a educação em ciências, imersos em efeitos de colonialidade.

Para compreender as origens dos estudos decoloniais e pós-coloniais, Ballestrin (2013) faz um apanhado histórico de ambos, identificando alguns autores e suas teorias, bem como a diferença entre esses dois grupos de estudos. O giro decolonial "originalmente cunhado por Nelson Maldonado-Torres em 2005" (BALLESTRIN, 2013) está vinculado ao grupo Modernidade/Colonialidade, que surgiu a partir do extinto grupo "Latino-Americano dos Estudos Subalternos". Já os estudos pós-coloniais são advindos de diferentes lugares, mesmo sabendo que não há como elencar os autores que mais contribuíram com essa escola, seguimos a linha de Ballestrin (2013) que aponta três teóricos que foram precursores dos estudos pós-coloniais que advogaram em favor do colonizado: Franz Fannon, homem negro da Martinica, psicanalista, lutou pelo processo de libertação da Argélia; Aimé Césaire também da Martinica, homem negro, poeta e Albert Memmi, nascido na Tunísia, homem branco, escritor e professor.

Barbosa (2018) aponta algumas nuances sobre o pensamento decolonial e a teoria póscolonial, que em resumo se diferenciam por seu contexto histórico, lócus de enunciação e bases teóricas. Como contexto histórico, os estudos decoloniais trabalham com questões postas pela colonialidade, já os estudos pós-coloniais atuam no meio que foi constituído pelo colonialismo. No lócus de enunciação o pensamento decolonial fala a partir da América Latina e Caribe nos séculos XVI a XIX, enquanto os estudos pós coloniais falam a partir da colonização da Ásia e África nos séculos XVIII a XX. Por fim, segundo Mignolo (2007) as bases teóricas do pensamento pós-colonial não rompem com os autores eurocêntricos, levando a crítica de que é necessário que esse rompimento aconteça para que possamos repensar a colonialidade.

Barbosa (2018) ao trabalhar com um país asiático - o Timor-Leste - busca diferentes referenciais teóricos, tanto do pensamento decolonial como da teoria pós-colonial, denominando esse processo de Crítico Antropofágico, em um movimento que se apropria "do pensamento decolonial latino-americano e das teorias pós-coloniais a fim de reinventá-los em termos locais" (ibid, 2018, p.78). Ao focar numa visão crítica antropofágica, o autor se filia a abordagens que tentam superar as visões coloniais, racistas e misóginas, utilizando os referenciais que buscam essas superações para a justiça social. Nesse sentido, podemos afirmar que muitas são as vertentes e se faz necessário dialogar com diferentes autores que lutam por problemas semelhantes em diferentes contextos.

Primeiramente falaremos sobre os tripés da teoria decolonial que discutem a colonialidade do poder, do ser e do saber. A colonialidade do poder está atrelada diretamente ao poder que os países colonizadores ainda têm sobre as antigas colônias, hoje países legalmente emancipados, porém com uma desigualdade que é também consequência dessa forma de colonização (MALDONADO-TORRES, 2007). A colonialidade do poder acarreta 
no fetichismo da cultura americana e europeia, levando os países colonizados a uma desvalorização do que é local, assumindo valores exógenos, favorecendo o racismo, o capitalismo e o patriarcado.

A colonialidade do ser está na "dimensão ontológica" da colonialidade do poder, sendo assim, está diretamente ligada às ações sofridas durante o período colonial, sendo uma de suas principais consequências o racismo estrutural que vivemos ainda nos dias atuais. Por fim, a colonialidade do saber é a que está ligada fortemente aos âmbitos acadêmicos, visto por exemplo na necessidade de publicações em inglês para que o conhecimento seja validado. Problematizando a educação em ciências, os livros didáticos, as imagens, as referências produzem uma imagem eurocentrada que apaga e silencia a diversidade que é o Brasil (PADILHA, 2017). Com isso, muitos dos saberes ancestrais e tradições acabam sendo esquecidos, apagados, o que gera um conhecimento baseado na neutralidade da ciência, branca e colonizada, gerando resultados muitas vezes desastrosos: desigualdades sociais, raciais, entre outros efeitos do capitalismo e globalização.

Cabe aqui destacar que dentro da área de pesquisa em educação em ciências, diversas(os) autoras(es) vêm pensando o ensino de ciências e de biologia em uma perspectiva decolonial e para a justiça social. Entre essas(es) autoras(es) podemos destacar os trabalhos de Carine e Katemari (2018); Cassiani (2018) e Nascimento (2017), que discutem a decolonialidade no ensino de ciências. E os trabalhos de Pagan (2018) e Verrangia (2014) que pensam o ensino de biologia na luta antirracista, feminista e em favor das dissidências sexuais e de gênero. Entre outras(os) autoras(es) que por questões de espaço não conseguimos mencionar aqui.

De acordo com a Análise de Discurso (AD) não há dissociação entre forma e conteúdo. O que se diz e a forma como se diz produz sentidos. Principalmente nas disciplinas de licenciatura é importante repensar a forma e o conteúdo, pois não se trata apenas de ensinar quais conteúdos e sua forma de ensinar. Com esse conceito da $\mathrm{AD}$ nos inspiramos numa metodologia que pudesse provocar outras escritas, abrindo espaços para a criatividade, integrando uma escrita fluída, não formatada pelos moldes acadêmicos, para (os) professoras(es) em formação.

\section{NARRATIVAS COLETIVAS E DIÁLOGOS COM VOZES MARGINALIZADAS NO ENSINO DE CIÊNCIAS}

Essa intervenção contou com a participação de dez professoras(es) em formação, e três professoras(es) formadoras(es): a professora da disciplina de estágio obrigatório de ensino de ciências e duas colaboradoras estagiárias docentes, bolsistas da CAPES, do Programa de PósGraduação em Educação Científica e Tecnológica. Como já dissemos e é importante ressaltar que nas aulas prévias a esta intervenção, ocorreram diversas discussões de textos sobre decolonialidade, luta antirracista, e dissidências sexuais e de gênero. Essa aula, em específico, teve uma duração de três horas e foi desenvolvida em dois momentos:

Primeiro momento: Iniciamos com uma apresentação expositiva e dialogada sobre a história do conceito hormônio, na perspectiva de Paul B. Preciado (2018), homem trans da Espanha, no seu livro "Testo Junkie: Sexo Drogas e biopolítica na era Farmacopornográfica”.

Abordou-se o capítulo do livro intitulado "Farmacopoder". Discutimos na a idade média e nos tempos da colonização das Américas, sujeitos e corpos racializados que possuíam conhecimentos ancestrais farmacológicos-espirituais (as bruxas, os povos indígenas e africanos) que eram de utilidade para os mais diversos objetivos, de sujeitos que autogestionavam seus saberes e prazeres corporais, passaram a ser corpos controlados e invisibilizados na produção de conhecimento e corpos de experimentação da ciência feita por pessoas brancas, especialmente homens. Tratamos especificamente o caso das mulheres de Porto Rico, mulheres racializadas, que foram "usadas" como cobaias pelas e pelos cientistas 
dos anos 50, para realizar os primeiros testes de pílulas anticonceptivas em humanos (ou melhor, em mulheres cisgênero) na vida cotidiana. Destacamos como para alguns cientistas da época, Porto Rico representava uma "jaula de fêmeas ovulando" (PRECIADO, 2018).

Abordamos também a questão de como a indústria farmacêutica tem sido orientada principalmente na intervenção do corpo considerado feminino, o corpo da mulher cisgênero. Intervenção com finalidades de controle, não só da "fertilidade" e "taxas de reprodução" desses corpos, mas também da mesma feminilidade e, inclusive, do seu prazer sexual. Já no corpo considerado masculino, esta intervenção, além de ser menor, não está direcionada ao controle da reprodução e do prazer, e sim, a manutenção de uma ideia de masculinidade relacionada a um alto desempenho sexual, exemplificado no caso do Viagra. Discutimos como para as ciências biológicas e médicas, parece natural o consumo de hormônios para controlar a sexualidade das pessoas (principalmente as mulheres cisgênero), mas se coloca como não-natural quando se trata de corpos de pessoas trans que por iniciativa própria procuram o consumo de hormônios.

Discutimos como poucas vezes estas conversas aparecem nas disciplinas nas quais são ensinados os conceitos de química, genética, farmácia, anatomia e endocrinologia que tem relação com as situações levantadas por Paul B. Preciado (2018). Pensamos sobre as condições que levam aos silenciamentos dessas discussões, e quanto é importante promover esses debates na formação de professoras(es) de ciências e biologia. Também refletimos sobre a importância de escutar e valorizar "vozes outras" silenciadas pelas relações históricas e coloniais na ciência, desmentir versões únicas da história da ciência, para promover diálogos com aqueles saberes que aprendemos na nossa formação, para pensar práticas docentes no marco da justiça social.

Como menciona Marin (2018) pensar a formação da(o) professora de biologia, mais do que uma questão de técnica, de adicionar outros conhecimentos, ou do reconhecimento dos grupos oprimidos, consiste na ressignificação do que aprendemos como biologia, seus valores e seu papel na escola e na sociedade. Também, como menciona Pinheiro (2019) um ensino de ciências (entre elas a biologia), comprometida com os dilemas e tensões sociais do seu tempo, necessita ter não só a consciência destas desigualdades, mas também promover ações que visem reduzir esses abismos, ou seja, lutar ou se posicionar contra essas injustiças, não ficando apenas numa postura contemplativa.

Segundo momento: Neste momento realizamos um diálogo com essas vozes silenciadas e corporificadas por sujeitos vítimas e resistências ainda, das relações coloniais de poder, ser e saber.

A narrativa coletiva, utilizada nesse contexto, teve como objetivo a construção de um texto que possa haver modificações via interpretação, visto que toda interpretação é passível de alteração de sentidos para o leitor (ORLANDI, 1996). Os autores então são leitores de si mesmo e do grupo como um todo. Ou seja, à medida que os textos são escritos e repassados para o próximo autor, novas leituras, novas provocações, outras compreensões do texto são possíveis. Caracterizando um texto com muitas formas e narrativas que conectam entre si.

As vozes que trouxemos para o diálogo foram as vozes de:

- Marlene Wayar (2007), ativista travesti e psicóloga social da Argentina, com uma parte do seu texto publicado no editorial da revista El Teje, considerado o primeiro periódico travesti da América Latina. Frase destacada: "Vocês têm que assumir! Vocês sempre erraram! Não tem molde para o ser! Vamos infectar vocês com a arte de ser."

- Oyèronké Oyěwùmí (1997), socióloga nigeriana pertencente ao povo Iorubá. Com o texto traduzido ao espanhol em 2007, intitulado "La invención de las mujeres: Una perspectiva africana sobre los discursos occidentales de género". Frase destacada: "O motivo pelo qual o corpo tem sido tão relevante para ocidente, é que o mundo é percebido principalmente pela visão... A observação convida a diferenciar." 
- Katú (2017), mulher indígena do povo Guarani, cantora de Hip Hop, com sua música intitulada Agüyjerete. Frase destacada: "Meu sangue é meu orgulho, não é sua aquarela, então... fora!".

- Siobhan F. Guerrero Mc Manus (2015), mulher trans, reconhecida bióloga do México, com seu texto intitulado "Las sexualidades naturales de la biología postmoderna". Frase destacada: "Por isso afirmo que existem as sexualidades naturais, todas, inclusive se todas estas são contingentes, plásticas, socialmente construídas e constituídas, historicamente situadas. São naturais, repito, porque todos esses processos são parte da história evolutiva do ser humano, uma história que é ecológica, material, mas também é histórica - social e simbólica de formas de governo, modos de produção, sistemas normativos, etc."

- Megg Rayara Gomes de Oliveira (2017), primeira doutora travesti negra do Brasil na área de educação, com sua tese de doutorado intitulada "O diabo em forma de gente: (r) existências de gays afeminados, viados e bichas pretas na educação". Frase destacada: "Se a categoria negrola reforça e até naturaliza a heterossexualidade, a categoria de homossexual é utilizada para confirmar a branquitude".

\section{CONDIÇÕES DE PRODUÇÃO DA PESQUISA}

A escrita coletiva, consistiu em fazer uma roda com o grupo de professoras(es) em formação, e professoras(es) formadoras(es). Entregamos aleatoriamente cinco folhas pelo grupo, cada folha continha na parte superior uma frase importante do texto das cinco vozes que trouxemos. A pessoa que recebia a folha devia ler a frase e continuar a escrita tentando construir uma história a partir do colocado pela autora. Cada dois minutos a folha passava para a pessoa que estava à direita, quem devia repetir o mesmo exercício, ler a história desde o começo e dar continuidade acrescentado sua voz. No final, produzimos então cinco textos/poemas/histórias/narrativas que lemos em voz alta e coletivamente para refletir sobre os sentidos mobilizados nessa escrita coletiva. Nesse trabalho, pela limitação de espaço deste texto, analisamos qualitativamente duas dessas narrativas tecidas coletivamente e os sentidos decoloniais mobilizados nestas escritas.

Cabe aqui destacar algumas premissas que adotamos para a análise desses textos. As autoras estão familiarizadas com a metodologia da análise de discurso à brasileira (ORLANDI, 2004). Para tanto, foram mobilizados alguns conceitos da AD, focando as escritas, considerando principalmente as condições de produção desses alunos, os silenciamentos nas escritas e a formação discursiva dos autores.

Para dar início a análise, iremos expor alguns conceitos importantes que utilizamos para essas análises, iniciando com os sujeitos autores dos textos. Consideramos que o sujeito é compreendido pela forma-sujeito, sendo a forma da "existência histórica de qualquer indivíduo, agente das práticas sociais" (ORLANDI, 2006, p. 18) A forma-sujeito é associada também a ideologia do sujeito, pelo simbólico, resultando em forma-sujeito histórica. Assim, o sujeito é constituído pela sua ideologia, contexto histórico e memória discursiva.

Para a $\mathrm{AD}$, no discurso não existe somente a decodificação da mensagem por parte do receptor, pois não se trata apenas de uma mera transmissão de informação que será decodificada e terá um único sentido. O discurso é compreendido como efeitos de sentidos entre interlocutores, que podem ser outros daqueles esperados em determinadas condições de produção. É palavra em movimento e a interpretação acontece de acordo com o conhecimento, história e expectativas dos sujeitos. A AD se fundamenta no funcionamento da linguagem e nessa perspectiva discursiva, a linguagem só é linguagem, porque há sentidos, que se inscrevem na história (ORLANDI, 2005).

Considerando que estes sujeitos foram autores durante essa intervenção, é necessário falar do que entendemos por autor. A noção de autor é uma "função do sujeito", sendo responsável pelos sentidos e pela unidade do texto (ORLANDI, 2006). A função autor então 
acontece sempre que um sujeito se coloca na origem de um texto, produzindo uma unidade textual, se aplicando ao "corriqueiro da fabricação da unidade do dizer comum, afetada pela responsabilidade social: o autor responde pelo que diz ou escreve, pois é suposto estar na origem" (ORLANDI, 2006, p. 24). Levando em consideração a autoria, os estudantes se colocam como sujeitos autores nas frases que escreveram ao longo da intervenção, produzindo assim a unidade textual analisada.

A unidade textual em questão é um conjunto de sujeitos autores. Sendo assim, analisamos a unidade textual que propusemos, considerando as diferentes colocações dos autores, mas sem envolver o sujeito empírico dessas colocações e sim as compreensões que advém dos textos. Essa unidade textual é chamada de corpus de análise, sendo a nossa unidade significativa para a investigação. Do ponto de vista empírico o texto é um objeto com início, meio e fim, mas para o discurso isso não está dado, é a incompletude do texto que o associa com as perspectivas do discurso, pois nem o sujeito, nem o discurso, nem os sentidos estão completamente fechados. Ainda assim, consideramos para a análise que o texto é uma construção inteira, se tornando um objeto completo para análise, visto que possui relação com as condições de produção, interdiscurso e exterioridade.

Orlandi (2005) afirma que não é possível a neutralidade de um analista quanto a sua interpretação de análise, mas que é esperado um deslocamento do sujeito, tentando ao máximo um olhar exteriorizado para os textos, um olhar que leva à compreensão do texto e não apenas a interpretação. Isso demonstra a alteridade do investigador em mudar de lugar, se deslocar, tornando-se então analista.

\section{BRANQUITUDE E CISGENERIDADE PROBLEMATIZADAS NAS NARRATIVAS TECIDAS COLETIVAMENTE}

Apresentamos aqui as transcrições de dois dos cinco textos coletivos escritos pelo grupo, e ressaltamos alguns sentidos decoloniais sobre a branquitude e a cisgeneridade mobilizados na escrita coletiva, os quais foram trabalhados ao longo do semestre.

Texto 1 (Sem título). Tecido a partir da fala da Oyèronké Oyěwùmí (Nigéria)

“O motivo pelo qual o corpo tem sido tão relevante para ocidente, é que o mundo é percebido principalmente pela visão... A observação convida a diferenciar." "A busca por um corpo perfeito, dentro dos padrões, tendo principalmente o ocidente como espelho/modelo, tem na produção de sentidos o eurocentrismo. Esse convite de uma forma de olhar outra, transforma corpos e mentes, promovendo mais empatia para ver as outras pessoas como arte de ser e não se preocupar tanto por encaixá-las em caixas que os classifique. Paramos então de observar o externo, ele não representa o seu ser eu. Não podemos avaliar pois não queremos ser avaliados. Mas será que devemos então parar de observar? Ou talvez, devemos construir novos paradigmas, desde uma produção situada e politicamente engajada, ciente dos limites inerentes aos nossos "olhos ocidentalizados"! "Sulear", dentro dessa lógica, torna-se cada vez mais necessário...É criar e pensar paradigmas com todos os sentidos, o tato, a escuta, o medo, o prazer. É pensar a partir do corpo, com o corpo e não sobre o corpo. A natureza que nos cerca, nos conectando com o interno para depois com os seus, sobre o autoamor que não pode ser capitalizado, nem instaurado no comércio, mas pode vir a ser. O ser está em nossas entranhas, na sabedoria do corpo, que podemos acessar e transbordar, quem não está vindo, está sentindo, mas a observação convida a diferenciar, então fechemos os olhos".

Compreendemos que esta escrita coletiva provocada pela colocação da Oyèronké Oyěwùmí mobilizou nas professoras(es) um traslado no foco na problematização daqueles consideradas(os) diferentes, para questionar padrões de normalidade e universalidade, neste caso, a branquitude. Falas como "A busca por um corpo perfeito, dentro dos padrões, tendo principalmente o ocidente como espelho/modelo, tem na produção de sentidos o 
eurocentrismo", denunciam legados decoloniais que se escondem por trás das hierarquizações estéticas de beleza e de normalidade nos corpos. A branquitude passa aqui a ser concebida como busca, desejo e construção simbólica e subjetiva, tendo o ocidente como modelo, reafirmando uma colonialidade do ser.

Outra questão interessante a ressaltar, é por que as pessoas escolheram esses dizeres e não outros? As condições de produção de sentidos durante a produção desse material, ou seja, uma turma de estágio, quase no final do curso, com abertura para trabalhar temas que vêm sendo polêmicos e com tentativas de silenciamentos por movimentos do tipo "escola sem partido", permitiram o dizer sem censura.

A presença no texto de construções, como a cisgeneridade e a branquitude, podem ser problematizadas como construções identitárias que nos cegam ou que nos limitam, pois ocidentalizam nosso olhar. Baseados em nossas leituras da realidade social, muitas vezes, não enxergamos as desigualdades, re-existências, rebeldias, estratégias com as quais vivem e sobrevivem corpos negros, indígenas e dissidentes das normas de gênero e sexualidade.

Na colocação "Mas será que devemos então parar de observar? Ou talvez, devemos construir novos paradigmas, desde uma produção situada e politicamente engajada, ciente dos limites inerentes aos nossos olhos ocidentalizados, compreendemos que surgiu a necessidade de reconhecer essas limitações e de pensar paradigmas outros, para uma práxis política engajada". Mesmo não aparecendo explicitamente no texto, podemos supor que estes paradigmas novos fazem referência a pensar outros olhares, outros sentidos, outras epistemologias, saberes, discursos e performances construídos por esses corpos que foram colocados como os diferentes e fora da norma, mas que na sua resistência anticolonial têm construído diversos saberes dos quais devemos aprender e com os quais devemos construir pontes e diálogos (NASCIMENTO, 2017) no ensino de biologia.

Como movimento decolonial, percebemos que na escrita coletiva foi explorada a possibilidade de corporificar nossa construção de conhecimento e nossas práticas de ensino e de aprendizagem. É preciso, colocar nossos lugares como corpo-políticos na produção de conhecimento (GROSFOGUEL, 2006) e corporificar a pedagogia (HOOKS, 1994). É pensar a partir do corpo, com o corpo e não só sobre o corpo.

Reconhecer que a educação e a ciência também têm corpo. Não se trata unicamente de uma atividade mental de privilegiados(as), mas também de experiências vivas que se nutrem de nossas vivências corporais.

Texto 2 (Sem título). Tecido a partir da fala da Siobhan F. Guerrero Mc Manus (México) "Por isso afirmo que existem as sexualidades naturais, todas, inclusive se todas estas são contingentes, plásticas, socialmente construídas e constituídas, historicamente situadas. São naturais, repito, porque todos esses processos são parte da história evolutiva do ser humano, uma história que é ecológica, material, mas também é histórica - social e simbólica de formas de governo, modos de produção, sistemas normativos, etc." "Todas as formas de expressão sexual deveriam ser olhadas e sentidas, dessa forma poderíamos nos conhecer a nós mesmas, pois somos seres naturais, não construídos, ideologizados. Somos muitos, diferentes e de todas as cores, cheiros e sabores, ainda assim parte de um todo. Bonito é ver e viver com todas as nuances da existência. Bonito é ver, é viver, mas mais bonito seria se não precisássemos de nossos olhos para perceber as nuances. Nuances essas que nos fazem únicos, lindos, cheios de histórias! Histórias que precisam ser respeitadas e aceitas na sociedade, independente da sexualidade, do gênero, cor da pele ou qualquer sentido batizado de "diferente". As histórias de vida, todas as vidas contam, são extremamente importantes. É triste ver o que aconteceu em nossa sociedade, por falta de compreensões e pelo ódio cada vez mais disseminado. Se a gente tem uma missão como professoras e professores de biologia é ensinar a biologia do amor, a de verdade, a que 
ensina que a diferença é que permite a vida. Biologia comprometida com as lutas sociais das, des e dos oprimidos e além disso, uma biologia humanizada, menos classificadora e idealista. Quando falamos de biologia, falamos de vida e de diversidade. Sejamos então coerentes com esses princípios. Por fim precisamos lembrar que a biologia é linda e potente, mas é uma postura ética perceber os limites inerentes ao seu fazer. Só assim poderemos utilizar todas as suas potencialidades, levando-se em conta todas/todos e todes, na construção do conhecimento."

A fala inicial da Mc Manus (2015) mobilizou um debate entre as(os) professoras(es) sobre o que é a biologia, e qual seu lugar no entendimento das dissidências sexuais e de gênero, trazendo um debate de longa data, o qual perguntamos: Cisgeneridade, transgeneridade, heterossexualidade, bissexualidade, intersexualidade... se tratam de assuntos de natureza ou de cultura? No mesmo texto, assim como encontramos frases do tipo "somos seres naturais, não construídos, ideologizados", também encontramos outras frases mencionando "por fim precisamos lembrar que a biologia é linda e potente, mas é uma postura ética perceber os limites inerentes ao seu fazer. Só assim poderemos utilizar todas as suas potencialidades". Permitindo discutir se o biológico se trata do natural como algo independente da cultura, ou se cultura e biologia se misturam na construção do que é a natureza humana e, portanto, todas todes e todos nós somos naturais.

Nesse sentido, a pré-discursividade e a binariedade como traços da cisgeneridade (VERGUEIRO, 2015) foram colocados em conflito e problematizados, tensionando ao mesmo tempo, os entendimentos que temos sobre o que é "biológico" ou "natural".

Para os estudos decoloniais, a colonização nos é imposta desde o período do colonialismo até os dias de hoje. Esta narrativa coletiva nos traz uma crítica sobre as diferenças raciais, que foram construídas com a ajuda da própria ciência moderna, tendo seu conceito de raça atribuído legitimidade às relações de dominação impostas pela colonização.

Ao mesmo tempo podemos enfatizar que o texto fala sobre "a diferença é que permite a vida", questionando a forma como o discurso é passado hoje em dia, principalmente vinculado à mídia, de que "somos todos iguais". Para nós, esse discurso acaba invisibilizando as diferentes culturas, os privilégios sociais e o racismo estrutural que nos constitui.

Pensando na educação em ciências e biologia, a construção do conhecimento precisa dialogar com os conhecimentos locais, promovendo o diálogo de saberes com os estudantes da escola básica. Para isso, é necessário também entender a conjuntura do país em que vivemos e nos espelhar em países que possuem essa conjuntura em comum. Sendo assim, é possível transpor um conhecimento europeu/estadunidense para nossas pesquisas e no ensino em sala de aula? Se não, como podemos fazer isso, ou seja é como produzir uma educação em ciências na América Latina, pensando nos nossos problemas e não importando problemas de outros países? O que podemos aprender e como podemos potencializar em nossas práticas educativas, pedagógicas e didáticas, aprendendo de outras vozes, aquelas vozes sempre silenciadas e marginalizadas?

\section{CONSIDERAÇÕES TRANSITÓRIAS}

Destacamos que a escrita coletiva mobilizada por vozes construídas pelas relações coloniais como periféricas, produziu debates e tensões sobre assuntos tradicionalmente pouco assumidos na formação de professoras(es) de biologia. É comum que os assuntos de gênero e sexualidade e das relações étnicorraciais, sejam principalmente abordados em uma perspectiva normativa, higienizada ou de respeito e inclusão. Nas narrativas coletivas, evidenciamos que outros sentidos importantes para o exercício decolonial surgiram, tais como a valorização desses corpos como sujeitos de saber, e a problematização da identidade branca e cisgênera, construídos subjetivamente em uma fantasia de neutralidade e universalidade, 
problematizando alguns privilégios e estruturas coloniais que se escondem na construção da branquitude e da cisgeneridade.

Podemos mencionar que a contradição faz parte fundamental das escritas coletivas. Narrativas que dão conta de interações sociais nas quais a autoria coletiva nem sempre representa um pensamento homogêneo. Aliás, sabemos que mesmo na autoria individual, os sentidos não são homogêneos ou estáticos, já que a linguagem não é transparente, os textos podem ser interpretados de outras formas mobilizando diversos sentidos.

Evidenciamos que disciplinas que discutem questões como as propostas e dialoguem com os espaços escolares, como os estágios supervisionados, podem se constituir como processos importantes na formação de professoras(es) de biologia, territórios de problematização de legados coloniais sobre nossas identidades na branquitude e na cisgeneridade. Os estágios supervisionados podem constituir oportunidades para discutir as estruturas de opressão e de desigualdade construídas social, cultural e historicamente pelo colonialismo e pela colonialidade que ainda se mantém. Da mesma maneira, destacamos que problematizar a cisgeneridade e a branquitude pode contribuir a que professoras(es) brancas e cisgêneras reflitam sobre suas identidades, sobre os valores e características da biologia como ciência ocidental, e, sobre seu papel no combate às desigualdades sociais e as discriminações opressões que marcam suas alunas(es) no exercício da docência.

\section{AGRADECIMENTOS}

Aos estudantes autores das narrativas, à CAPES e ao CNPq.

\section{REFERÊNCIAS}

BARBOSA, Alessandro. (De)Colonialidade no Currículo de Biologia do Ensino Secundário Geral Em Timor-leste. Tese de doutorado. Florianópolis- SC, 2018.

BRASIL. Resolução $N^{o}$ 2, de $1^{\circ}$ de julho de 2015. Diretrizes Curriculares Nacionais para a formação inicial em nível superior (cursos de licenciatura, cursos de formação pedagógica para graduados e cursos de segunda licenciatura) e para a formação continuada. Brasília, DF, 2015.

CARDOSO, Lourenço. Branquitude acrítica e crítica: A supremacia racial e o branco antirracista. Revista Latinoamericana de Ciencias Sociales, Niñez y Juventud, v. 8, n. 1, p607-630, 2010.

BALLESTRIN, Luciana. América Latina e o giro decolonial. Revista Brasileira de Ciência Política, n. 11, p. 89-117, 2013.

CARINE, Bárbara; KATEMARI, Rosa (Orgs.). A Lei 10.639/2003 no ensino de ciências. Descolonizando saberes. Editora Livraria da Física: São Paulo, 2018.

CASSIANI, Suzani; NASCIMENTO, Tatiana G. Um diálogo com as histórias de leituras de futuros professores de Ciências. Pro-Posições (Unicamp), v. 17, p. 105-136, 2006.

CASSIANI, Suzani \& LINSINGEN, Irlan. Formação inicial de professores de Ciências: perspectiva discursiva na educação CTS. Educar em Revista [online]. n.34, pp.127-147, 2009. Acesso em 03/06/2020: https://doi.org/10.1590/S0104-40602009000200008. 
GROSFOGUEL, Ramón. Para descolonizar os estudos de economia política e os estudos póscoloniais: transmodernidade, pensamento de fronteira e colonialidade global. Revista Crítica de Ciências Sociais, n. 80, p. 115-147, 2008.

GROSFOGUEL, Ramón. La descolonización de la economía política y los estudios postcoloniales: transmodernidad, pensamiento fronterizo y colonialidad global. Tabula rasa, n.4, p. 17-46, 2006.

HOOKS, Bell. Teaching to transgress. Education as the practice of freedom. Nova York: Routledge. 1994.

KATU. Agüyjerete. Clipe musical, 2017. Disponível em: https://www.youtube.com/watch?v=M4czt2327vA. Acesso em: 10 nov. 2019.

MALDONADO-TORRES, Nelson. "Sobre la colonialidad del ser: contribuciones al desarrollo de un concepto", In: CASTRO-GÓMEZ, Santiago \& GROSFOGUEL, Ramón (org.) El giro decolonial: reflexiones para uma diversidad epistêmica más allá del capitalismo global. Bogotá: Siglo del Hombre Editores; Universidad Central, Instituto de Estudios Sociales Contemporáneos, Pontificia Universidad Javeriana, Instituto Pensar, p.7991. 2007.

MARIN, Yonier A. Orozco. Las experiencias de vida de personas transgénero y transexuales: Diálogos posibles con la enseñanza de las ciencias naturales. Tecné Episteme y Didaxis: TED. Colômbia, 2018.

MC MANUS, Siobhan. Las sexualidades naturales de la biología post-moderna. In: RUIZ, R.; MC MANUS, F.; FOULKES, B.; LAMAS, M. Sexualidad: Biologìa y cultura. Primera ediciòn. Universidad Nacional Autônoma de México, n.8, p. 35-61, 2015.

NASCIMENTO, Carol. Reflexões sobre a Natureza da Ciência à luz das Epistemologias do Sul. In: XI Encontro Nacional de Pesquisa em Educação em Ciências - XI ENPEC, Florianópolis, Anais, 2017.

OLIVEIRA, Megg. O diabo em forma de gente: (R)existências de gays afeminados, viados e bichas pretas na educação. Tese de Doutorado. Programa de Pós-Graduação em Educação da Universidade Federal do Paraná, Curitiba, 2017.

ORLANDI, Eni. Interpretação: autoria, leitura e efeitos do trabalho simbólico. Petrópolis: Vozes, 1996.

Análise de discurso: princípios e procedimentos. Campinas: Pontes, 2005. . Discurso e textualidade: Introdução às ciências da linguagem. Campinas:

Pontes, 2006. 
OYĚWÙMÍ, Oyeronke. The Invention of Women: Making an African Sense of Western Gender Discourses. Minneapolis: University of Minnesota Press, 1997. Tradução de Alejandro Montelongo González. La invención de las mujeres. Una perspectiva africana sobre los discursos occidentales del género. Bogotá: En la frontera, 2017.

PADILHA, Raíza. Pela superação da colonialidade do saber: o conceito de biomas em livros didáticos de ciências. Trabalho de conclusão de curso. Florianópolis - SC, 2017.

PAGAN, Alice. O ser humano do ensino de biologia: Uma abordagem fundamentada no autoconhecimento. Revista entreideias, v. 7, p. 73-86, 2018.

PRECIADO, Paul. Testo Junkie: Sexo, Drogas y Biopolìtica na era farmacopornogràfica. Traduzido por Ribeiro M. São Paulo: n-1 edições, 2018.

PIMENTA, S. O estágio na formação de professores: unidade teoria e prática. $3^{\mathrm{a}}$ ed. São Paulo: Cortez, 2002.

SCHUCMAN, Lia. Entre o "encardido", o "branco" e o "branquíssimo": Raça, hierarquia e poder na construção da branquitude paulistana. Tese de Doutorado em Psicologia, Universidade de São Paulo. 2012.

VERGUEIRO, Viviane. Por inflexões decoloniais de corpos e identidades de gênero inconformes: uma análise autoetnográfica da cisgeneridade como normatividade. Dissertação de Mestrado, Programa Multidisciplinar de Pós-Graduação em Cultura e Sociedade, Universidade Federal da Bahia. 2015.

VERRANGIA, Douglas. Educação científica e diversidade racial: O ensino e a pesquisa em foco. Interações, n. 31, p. 2-37, 2014.

WAYAR, Marlene. Editorial. El teje, v.1, n.1, 2007, p-2-3.

WAYAR, Marlene. La visibilidad de lo invisible. In: BERKINS, Lohana. Cumbia, copeteo y lágrimas: Informe nacional sobre la situaciòn de las travestis, transexuales y transgéneros. A.L.I.T.T. Asociaciòn de lucha por la identidad travesti-transexual. Buenos Aires, 2007.

WALSH, Catherine. Interculturalidad crítica y pedagogía de-colonial: apuestas (des)de el insurgir, re-existir y re-vivir. In: MEDINA, P. Educación intercultural en América Latina: memorias, horizontes históricos y diyuntivas políticas. México: Plaza y Valdés, 2009. p. 2542. 